\title{
Parents and Teachers Engagement in Using Cognitive Apprenticeship for Child's Development of Authentic Problem- Solving Skills in Tanzania
}

\author{
Pambas Tandika Basil ${ }^{1, *}$
}

\author{
${ }^{1}$ Department of Educational Psychology and Curriculum Studies, College of Education, the University of Dodoma \\ Tanzania. \\ *Corresponding author. Email: tpambas@gmail.com
}

\begin{abstract}
Despite its recognition in the pre-primary curriculum and being among preferred learning outcomes at different levels, it is not well-known how child's teachers [parents and classroom teachers] engage to enhance children with authentic problem solving skills. Phenomenography study design was used to investigate and reveal use of cognitive apprenticeship by involving 12 parents and nine classroom teachers who were sampled purposely because of their stake in the level of education. Data were collected through individual in-depth interviews and two focus group discussions [FGDs] to teachers and parents respectively in Konawa district. Thematic content analysis obeying three-steps-open coding, axial coding and selective coding - introduced by Strauss and Corbin (1990) was applied. Findings reveal that classroom teachers differed with parents on strategies they used to enhance a child's problem solving skills. However, work environment, policy-related issues, and child-related issues impacted classroom teachers' on their initiatives in nurturing children to become good problem solvers; while economic status, lack of parental knowledge and diseases affected parents' initiatives on the same. The study concludes that development of children with authentic problems requires a working environment as well as policy specification be improved to achieve it.
\end{abstract}

Keywords: Problem solving, cognitive apprenticeship, pre-primary education.

\section{INTRODUCTION}

Generally, the triad of teacher(s), learner(s) and the environment is essential in effective teaching and learning at any level. Yet, in practice, teachers (school/classroom and parents) play a pivotal enabling role to ensure effective learning occurs and for the children, eventually, to solve problems they encounter. Webster-Stratton and Reid [1] assert that empirical evidence suggests that learning geared towards empowering the learner to solve problems, prevent and reduce challenging behaviour in children requires the use of multiple ways such as preschool or childcare. Significantly, Gutierrez [2] recognises parents and caregivers as the first and most important teacher modelling to solve problems by yelling, throwing things, hitting, grabbing or using other unacceptable strategies, as such scenarios would make a child learn to do the same thing. After all, the child imitates and critically gets ready for school.

Three strategies for teaching problem-solving skills at any age. The first strategy entails modelling through "think-aloud", which engages a child to think of a solution of the particular problem of the real-world encountered by the parents/caregiver and/or him or herself [3]. In this regard, the collaboration between the child and the adult in solving a problem, such interaction occurs in both preschool and family contexts [4] and influences children's thinking and learning [5]. The second strategy involves asking a child to provide advice when an adult has a problem and such a process teaches him/her that making mistakes and facing challenges as well as practicing problem-solving skills are an integral part of the human experience. The third strategy that provides requires the teacher (parent or classroom teacher) not to provide the answer(s) to questions; instead, he or she lets the child struggle until learns to solve problems from the consequences experienced. These three strategies facilitate equipping children with problem-solving skills as they engage them in the processes of the work, observing adults or the experienced folk performing a task (e.g. sowing, planting, and harvesting crops). They also participate by helping someone to accomplish the task. This cognitive apprenticeship (CA) makes thinking visible in the actions the children observe and participate in [6]. The use of this 
kind of instruction tends to reduce teacher domination in the teaching and learning process, hence a shift towards the learner-centred philosophy, and particularly, pushing literally "the burden of learning from teachers" to the shoulders of learners. The shift of the burden of learning to shoulders of learners is done through the gradual release of the responsibility [GRR] model propounded by Pearson and Gallagher [7] for empowering children to become active constructors of knowledge.

In fact, this social interaction in an authentic environment targets the development of authentic problem-solving skills between the learner and the more knowledgeable other [MKO] — be it a parent, sibling, or and the teacher facilitate novices [children in this case] become experts. Authentic problem-solving skills are among the crucial skills that a child demonstrates as early as from 18 months. The skills are foundational in the development of other skills and success in educational settings [8].

It is in this realization that prompted the United Republic of Tanzania-URT [9] to focus one of the nine objectives of the pre-primary education [PPE] curriculum on developing children's creative and logical thinking skills through mainly play-based teaching and learning. However, research on the development of such skills to PPE children in Tanzania has not focused on revealing how educators (parents and teachers) get involved through $\mathrm{CA}$ in enhancing authentic problem-solving skills essential for a child's future learning and employability. Though the available research by Mandama [10] and Kitta and Kapinga [11] acknowledge the importance of developing children with problemsolving skills, they did not focus on the use of the CA in the process. Whereas Mandama [10] determined that preprimary teachers in selected schools in Rombo and Mwanga districts developed children's problem-solving skills in reading, writing and simple arithmetic through songs, demonstrations, and directive scaffolding; Kitta and Kapinga [11] just dwelled on the importance of equipping children with problem-solving skills prior to academic skills.

Lack of such empirical experiences characteristics this critical level of education with less lessons to use for nurturing children with the authentic problem-solving skills. Adversely, limited opportunity to engage children through CA experiences would further impact on their future learning and interaction. Thus, this study was designed to contribute knowledge in the field and for child's readiness for schooling.

\subsection{Research Questions}

The study was guided by two specific research questions:
1. What means do educators use to model learners towards acquiring higher thinking skills?

2. What challenges do they encounter when engaging children to develop authentic problem-solving skills?

\subsection{Significance of the Research}

This study is significant at multiple levels to parents, curriculum developers and decision-makers on the teachers' preparation and professional development so that plans they developed to facilitate children's acquisition of problem-solving skills from a both practical and policy perspective. Developing and enhancing children with problem-solving skills is critical in personal learning and for societal benefit, as children who do not acquire problem-solving skills during early childhood years tend to be more aggressive towards other people and, finally, tend to contend with social problems such as peer rejection, criminal behaviour, and mental health problem in adulthood [12]. In consequence, they would inadequately contribute towards giving solutions to problems impacting family/society and entire society due to their inability to engage successfully in socioeconomic activities for lack of skills. It is well known that problem-solving is one the crucial skills employers across the world value in the $21^{\text {st }}$ century. Developing children's problem-solving skills could reduce the burden of their future employability and the nation gets relieved from carrying a burden of unemployable youth lacking innovativeness and life survival skills.

\section{METHOD}

\subsection{Study Design}

This study was guided by the phenomenography study design as its principle stance is to reveal and investigate the different ways in which people experience phenomena in their world. The design fitted well this study as it aimed to uncover ways parents and preprimary teachers develop children as problem solvers. Its use was as necessary as it allows researchers who attempt to capture the critical differences in how people experience and learn to experience the world. It has a central assumption that explains that there is variation in people's experiences of the same thing.

\subsection{Data Collection}

The study used in-depth interviews and focus group discussions [FGDs] with nine classroom teachers and 12 parents. Individual in-depth interviews were held with teachers. These interviews allowed the interviewer to delve deeply into their experiences in equipping children with problem-solving skills whereas use FGDs with parents facilitated collecting data from parents by 
determining their knowledge of or parenting experience in nurturing and raising children amenable to developing problem-solving skills by integrating the interaction dynamics in each group. Data from both interviews and FGDs were recorded in a notebook for further analysis. On average, both the interview and FGDs lasted for 60 minutes.

\subsection{Sample Size and Sampling Procedures}

The study involved a total of 21 participants who were sampled purposely as they are the ones who actuate the PPE curriculum (classroom teachers) and had children in pre-primary classes (parents). The involvement of family members and teachers served as people with more knowledge and experiences in their contexts, home and schools respectively.

\subsection{Ethical Considerations}

The study adhered to ethical considerations and research protocol. Before this study was conducted, participants were informed about the purpose of this study and voluntary nature of their participation before obtaining their informed consent. Moreover, they were assured of confidentiality with identification markers not included to prevent their being linked to the information they provided. Significantly, research clearance was obtained from the authorities prior to undertaking the research.

\subsection{Data Analyses}

The resultant data was subjected to thematic content analysis. This data analysis involved three-steps-open coding, axial coding and selective coding-introduced by the [13]. The analysis process encompassed reading at least twice each transcript to identify core concepts. Codes were then assigned for the selected texts after data familiarisation that enabled concepts identification. This was further developed by adding sub-themes which were followed by detailed coding.

\subsection{Location of the Study}

This study was conducted in one ward in Kongwa district among seven districts constituting Dodoma region. Nine schools and parents from two villages were involved. The district was chosen as it has been engaged using diaries to link parents and teachers for shared roles of education and supporting children reach their fullest potentials [14]. Kongwa district was also selected as it has been involved in several educational programmes to empower parents on their role in educating and enrolling children for pre-primary. One of the programmes is the Children's Book Project (CBP) programme funded by Pestalozzi Children's Foundation [15].

\section{RESULTS}

\subsection{How Educators Model Learners on Higher Thinking Skills}

Analysis of the results on the way educators (parents and pre-primary teachers) model children on the development of higher order thinking skills reveals two sub-themes. The constructs are educators' understanding of higher order thinking skills and means or strategies they use to promote child's problem solving skills. The following subsections present details of the two subthemes.

\subsubsection{Understanding on higher order thinking skill}

Teachers understood and explained higher-order thinking skills as thinking that entails understanding the issue in detail and analyse it for easy identification of the means to solve the challenges or problems. Some treat higher order thinking skills as creativity in addressing issues. Whereas teachers held such views, parents treated it as one of the essential skills children need to solve challenges they encounter.

Data analysis reveals that teachers largely characterised a critical thinking child as one who asks and answers questions (curious), one who is creative in attempting to deal with issues that translates into their efficiency and precision. In doing so, a child develops competency in several things that enable him/her to solve different challenges coming at him/her. Similarly, parents described a critical child as one who observes and asks questions on things they observe. In relation to their characterisation, both parents and teachers associated playing various games or engaging in activities with a capacity to develop children's varied skills capable of making them solve challenges they encounter.

\subsubsection{Means teachers use to develop children's problem-solving skills}

Regarding their strategies for enabling children to become problem solvers, teachers and parents differed on their involvement mechanisms. Teachers on their side reported being friendly to the children, particularly using teaching and learning strategies that place the child at the centre of the teaching and learning in addition to being close to them, which make them feel free to work with the teacher, hence, easily develop collaborative attitudes that enhances confidence to engage in problem-solving situations. Parents reported ensuring that children have all the necessary school materials, engage in educating proper keeping of such materials for sustainable use in school and learning at home. Looking at the parents' way of nurturing children to develop problem-solving skills, it ends on ensuring that they have the school essentials 
but it does not engage children in some activities essentially targeting problem-solving development skills. Lack of parents' awareness on appropriate ways to nurture children as problem solvers emerged during the study, one of the parents said:

I used to help the child during the evening to attempt questions given as homework and, sometimes, I use the textbook to teach him or her so that when in school does not fail or be behind others.

Guidance and counselling [G\&C] emerged as their shared way of enabling children to develop problemsolving skills. However, how they applied G\&C to nurture children into problem solvers differed. Parents, for instance, reported to use G\&C to show them the good way of living with others and behaving in an acceptable manner as expected by family members and the society. To some extent, parents reported using G\&C to explore child's development and learning difficulties they encountered so that they could help to address them. In contrast, teachers used G\&C to empower children on the best way of solving the problems they encountered. Both teachers and parents reported using $\mathrm{G} \& \mathrm{C}$ to build a child's confidence and mental health that could be necessary in learning and addressing problems.

In addition to using the $\mathrm{G} \& \mathrm{C}$ as a strategy for building a child's strong mental health; the participants, particularly parents, reported good diet as important. In this regard, parents shared their experiences of preparing good diets for their children to grow strong physically and mentally so that diseases that emerge because of the uptake of poor diet do not cripple them. So by being healthy, parents noted, was a good way for children to learn and become capable of solving problems. Teachers on their part shared that where they noticed learning difficulties in a child, they invited the parent or guardian and discussed the essential steps to enable the child to cope with others and excel as expected.

\subsection{Challenges Impacting Teachers' and Parents' Nurturing Children as Problem- Solvers}

Analysis of the data collected through in-depth interviews with teachers revealed that the work environment, policy-related issues, and child-related issues impacted on their initiatives in nurturing children to become good problem solvers. On their part, parents indicated economic status, lack of parental knowledge and diseases as crucial factors affecting their initiatives aimed to nurture children as problem solvers.

\subsubsection{Teaching and learning environment}

The teaching and learning environment was explained by classroom teachers to impact differently to fulfil their plans of developing children as problem solvers. Specifically, many children enrolled hindered teacher's plans for individualised teaching and learning. Consequently, it was hard for the teachers to scaffold and mediate learners' experience as they found it difficult to realise their learning potentials and limitations. Having many children using one room for learning accompanied with fewer pre-primary teachers' limits use of learnercentred learning as in most cases each of them taught more than 100 children. Meanwhile, this teacher was also required to teach upper primary classes. In such a situation, these teachers' experienced heavy teaching load and, as a result, they inadequately prepared for the following day's lessons. Indeed, overcrowded class affects the appropriate arrangement of learning materials for children to access and use resources designed for child-centred learning. Whereas teachers contended with a hostile working environment, parents identified poverty as a contributory factor to their failure to meet the children's individualised needs (playing materials, consistently offering good diet etc), which in turn dwarfed their children's cognitive tendencies of natural players and observers. As one of the parents illustrated:

You find that I am alone as a parent with all the responsibilities of keeping the family with particular focus on keeping children in good condition, that is, financially and provide them learning space, but I fail to meet the required and basic needs. This impact on my children to develop and learn as other children whose home place is stimulating with most of the learning materials found.

Being a single parent does not only impact parents in nurturing children, a parent is overloaded with responsibilities that reduce his/her interest to engage with the child in learning as the parent tends to be busy searching for the family bread. Due to the inability to ensure the sustainable uptake of good diet at home, teachers reported that such children failed to think authentically and critically, let alone analysing issues, which is an essential step in problem-solving, which goes hand-in-hand with parents turning to be harsh accompanied with corporal punishment to their children that ends in instilling fear in the child when he/she sees the parent.

\subsubsection{Policy-related issues}

Lack of well-planned in-service training as a policy issue made teachers implement the curriculum inadequately, which goes together with the decreasing capacity and interest in making learning environments stimulating and with adequate child friendly as well as relevant materials for engaging children in authentic learning activities for solving problems. Lack of parental awareness or too laissez faire parenting of their children in a way that they lose power and control to make them focused was reported to be among the challenges to parents' and caregivers' initiatives fostering their 
children's capability of approaching and solving problems.

\subsubsection{Child-related challenges}

Good child's health conditions particularly being affected by chronic diseases was found to impact on the children and teachers (schoolteachers and parents as first and principal teachers) in meeting curriculum expectations. Diseases such as HIV/AIDS and sickle cell were reported as challenges to children that affected their regular class attendance and engagement in different learning activities assigned to them and on their own volition. Teachers shared their experience that when a child was affected by inheritable and/or infectious diseases they felt lonely and discriminated against; as a result, they lost interest in learning and their courage.

\section{DISCUSSION}

Mahmood [16] discounted parental hostility particularly being angry (confrontational, rude parents, whose reactions were unprovoked) and instead underscored their ability to listen actively, phrase positively, non-emotionality, and provision of constructive feedback to children as powerful means for enabling children to develop and enhance their ability to solve problems. Both parents and teachers identified the responsiveness of parents [17-20]. Teachers being informed and having passion with all the children to be crucial in child's development of logical thinking essential for problem-solving. In fact, parenting that provides positive affection and high levels of warmth are cognitively responsive to the child's needs, including the provision of rich verbal input and maintaining and expanding on the child's interests, providing a range of support necessary for multiple aspects of a child's learning.

Furthermore, the participants reported interactions engendered by active teaching and learning as well as parental engagement in the teaching and learning their children at home attested to their responsiveness that scaffolded a child's development independent [21]. Nevertheless, the study participants' responses focused on the low level of developing the child's capacity to solve critical problems. Gutierrez [2] identifies the steps that participants of this study did not mention among steps to include engaging children to solve problems. The steps are identifying the problem, listing the possible solutions or courses of action, weighing the possible solutions, choosing a solution to try, putting the solution into practice, and evaluating the solution. Lack of engagement of children in these crucial steps that enhance their ability to solve problems made it increasingly difficult for them to become thinkers and problem-solvers during their learning and future endeavours. Ensuring children are mentally and physically fit for analysing issues, as was identified by study parents, is an essential indicator for futurereadiness to learn and think critically when assessing options and making sound decisions in different ways [22].

\section{CONCLUSION AND RECOMMENDATIONS}

Based on the study findings as were shared by parents and teachers, the study found that the development of children into problem-solvers still had a long way to go despite the emphasis placed on the pre-primary curriculum of 2016. Until when there was an increased number of teachers working with the pre-primary, lack of motivation and self-drive to engage children in authentic problem-solving learning experiences would continue undermining learner-centred learning for young children. Secondly, improving parental awareness regardless of their status (single or economically poor) could help them to engage with children on different learning experiences at home for a connected experience of learning. Finally, the study calls for the involvement of teachers in ensuring children developed authentic problem-solving skills for further learning and national development.

\section{REFERENCES}

[1] Webster-Stratton C, Reid MJ. Strengthening social and emotional competence in young children - the foundation for early school readiness and success: Incredible year's classroom social skills and problem-solving curriculum. Infants \& Young Children. 2004 Apr 1;17(2):96-113.

[2] Gutierrez, E. Problem-solving skills are an important factor in academic success. Michigan State University. 2012. Available from: https://www.canr.msu.edu/news/problem_solving_s kills_are_an_important_factor_in_academic_succes s on $18 / 11 / 2020$.

[3] Pearson J, Hall DK. Partnerships to enhance children's problem-solving skills. Canadian Child Care Federation. Retrieved on July. 2008;10:2012. Available from: https://www.reaching inreachingout.com/documents/CCCF-Fallo8English.pdf.

[4] Harkness, S \& Super, C. Culture and parenting. In: Bornstein M, editor. Handbook of Parenting: Biology and Ecology of Parenting. Vol. 2. Mahwah, NJ: Lawrence Erlbaum Associates, Inc.;2002. pp.253-280.

[5] Sun J, Rao N. Scaffolding preschool children's problem solving: A comparison between Chinese mothers and teachers across multiple tasks. Journal of Early Childhood Research. 2012;10(3):246-66. Available from: https://journals.sagepub.com/ doi/pdf/10.1177/1476718X11415578. 
[6] Collins A, Brown JS, Holum A. Cognitive apprenticeship: Making thinking visible. American Educator. 1991;15(3):6-11. Available from: https://www.aft.org/ae/winter1991/collins_brown_h olum.

[7] Pearson PD, Gallagher MC. The instruction of reading comprehension. Contemporary Educational Psychology. 1983;8(3):317-44. Available from: https://www.ideals.illinois.edu/bitstream/handle/21 42/17939/ctrstreadtechrepv01983i00297_opt.pdf?se quence $=1,500,300$.

[8] Fettig A, Schultz TR, Ostrosky MM. Storybooks and beyond: Teaching problem solving skills in early childhood classrooms. Young Exceptional Children. 2016;19(3):18-31.

[9] United Republic of Tanzania. Curriculum and syllabus for pre-primary education. Dar es Salaam: Ministry of Education, Science and Technology; 2016.

[10] Mandama, A. Teachers' strategies for development of problem-solving skills among preschoolers in Kilimanjaro region, Tanzania. [Masters' Dissertation, the University of Dodoma]. Dodoma: The University of Dodoma; 2013.

[11] Kitta S, Kapinga OS. Towards designing effective preschool education programmes in Tanzania: What can we learn from theories? Journal of Education and Practice. 2015;6(5):180-5.

[12] Broidy LM, Nagin DS, Tremblay RE, Bates JE, Brame B, Dodge KA, Fergusson D, Horwood JL, Loeber R, Laird R, Lynam DR. Developmental trajectories of childhood disruptive behaviors and adolescent delinquency: A six-site, cross-national study. Developmental Psychology. 2003 Mar;39(2):222-245.

[13] Corbin JM, Strauss A. Grounded theory research: Procedures, canons, and evaluative criteria. Qualitative Sociology. 1990 Mar;13(1):3-21.

[14] Kapinga, O., Amani, J., Kitta, S., Kalolo, J \& John, $\mathrm{P}$. Promoting reading and arithmetic skills among standard one and two in Tanzanian primary schools: The role of home and classroom environment. Dodoma: Ministry of Education, Science and Technology and University of Dodoma; 2019.

[15] Tanzania Education Network/Mtandao wa Elimu Tanzania. Promoting children's rights to early childhood care and education in Tanzania: A baseline study report. 2014. Available from: http://www.tww.or.tz/documents/Publications books/ecce\%20baseline\%20study\%20booklet.pdf on $22 / 11 / 2020$

[16] Mahmood S. First-year preschool and kindergarten teachers: Challenges of working with parents. School Community Journal. 2013;23(2):55-86.
Available from: https://files.eric.ed.gov/ fulltext/EJ1028824.pdf.

[17] Ainsworth MD, Blehar MC, Waters E, Wall SN. Patterns of attachment: A psychological study of the strange situation. New York: Psychology Press; 2015.

[18] Grusec JE, Goodnow JJ. Impact of parental discipline methods on the child's internalization of values: A reconceptualization of current points of view. Developmental Psychology. 1994;30(1):4-19. Available from: https://psycnet.apa.org/doi/10.1037 /0012-1649.30.1.4

[19]Rogoff B. Apprenticeship in thinking: Cognitive development in social context. Oxford: Oxford University Press; 1990.

[20] Vygotsky LS. Mind in society: The development of higher psychological processes. Cambridge: Harvard university press; 1980.

[21]Malik SA. Revisiting and re-representing scaffolding: The two gradient model. Cogent Education. 2017;4(1):133-53.

[22] Ministry of Education. Nurturing early learners - A curriculum framework for kindergartens in Singapore: A guide for parents. Singapore: Preschool Education Branch, Education Services Division; 2012. 